\title{
Central Neuropathic Pain in Spinal Cord Injury
}

\author{
Sujin Lee ${ }^{1}$, Xing Zhao ${ }^{1}$, Maya Hatch ${ }^{2}$, Sophia Chun ${ }^{3}$, and Eric Chang ${ }^{1}{ }^{,}$ \\ ${ }^{1}$ Department of Physical Medicine and Rehabilitation, University of California, Irvine, CA \\ ${ }^{2}$ Reeve-Irvine Research Center, University of California, Irvine, CA \\ ${ }^{3}$ Spinal Cord Injury Medicine/Disease, Long Beach VA Hospital, Long Beach, CA
}

\begin{abstract}
Spinal cord injury (SCI) is a devastating medical condition affecting 1.2 million people in the United States. Central neuropathic pain is one of the most common medical complications of SCI. Current treatment options include opioids, antiepileptic agents such as gabapentin, antispastic agents such as baclofen or tizanidine, and tricyclic acid. Other options include complementary, nonpharmacological treatment such as exercise or acupuncture, interventional treatments, and psychological approaches. Although these treatment options exist, central neuropathic pain in patients with SCI is still extremely difficult to treat because of its complexity. To develop and provide more effective treatment options to these patients, proper assessment of and classification tools for central neuropathic pain, as well as a better understanding of the pathophysiology, are needed. A combination of approaches, from standard general pain assessments to medically specific questions unique to SCI pathophysiology, is essential for this population.

A multidisciplinary approach to patient care, in addition with a better understanding of pathophysiology and diagnosis, will lead to improved management and treatment of patients with SCI displaying central neuropathic pain. Here we summarize the most recent classification tools, pathophysiology, and current treatment options for patients with SCI with central neuropathic pain.
\end{abstract}

\section{Keywords}

central pain; neuropathic pain; spinal cord injury; pathophysiology; treatment

\section{Introduction}

Spinal cord injury (SCI) is a devastating medical condition affecting 1.2 million people in the United States, with an incidence rate of approximately 40 cases per million population or approximately 12,000 new cases each year. ${ }^{1}$ The incidence rate for SCI has been stable from year to year. However, because of advances in acute and chronic medical management resulting in a longer life span, the prevalence of SCI has been increasing. After acute hospitalization and rehabilitation phase, a majority of patients with SCI are discharged home

*Address all correspondence to: Eric Chang, MD, Department of Physical Medicine and Rehabilitation, University of California, 101 The City Drive, Bldg. 53 Rm 311A, Orange, CA 92868; Changey1@uci.edu. 
or to a long-term care facility. ${ }^{2}$ Once patients with SCI are discharged into the community, the burden of care for their medical issues are passed to primary care physicians who may not have the experience to care for this complex population. ${ }^{3}$

Of all the postinjury complications in patients with SCI, pain is one of the most difficult conditions to treat. ${ }^{4,5}$ The fundamental problem is that pain associated with SCI is complex and particularly problematic because several types of pain may exist simultaneously, and many of these are refractory to treatments that are currently available. Pain has been reported to affect up to $80 \%$ of patients with $\mathrm{SCI}^{6}$ and has significant negative effects on quality of life as well as cognitive, physical, and emotional functionality. ${ }^{7}$ The management of pain requires specific approaches that are not familiar to many primary care physicians. Unfortunately, this can compromise the quality of care and quality of life for many patients with SCI. The goal of this article is to provide an understanding of the treatment and management of central pain in patients with SCI by reviewing the classification of SCI pain, the pathophysiology of central neuropathic pain in SCI, and the guidelines for the management of central pain in SCI.

\section{Spinal Cord Injury Pain Classification}

Pain after SCI is a common sequela; however, the definition and classification of SCI pain has not been well established, leading to at least 29 different SCI pain classification systems. Since the prevalence of pain is based on identified pain types and classifications, estimates of the prevalence of various types of pain in SCI often are extremely variable and misleading. ${ }^{8}$ In an effort to develop a consistent and reliable SCI pain classification system, an international group of 15 basic science and clinical pain experts gathered together in 2012 to develop the International Spinal Cord Injury Pain (ISCIP) classification. ${ }^{9}$ Before this classification, the Bryce-Rangnarson or the Siddall SCI pain classification were the most widely used classification systems. Development of a clearly defined, unified pain classification system not only alleviates communication and labeling issues between clinicians, researchers, and health officials but also increases awareness and proper treatment of SCI pain.

The new ISCIP classification organizes SCI pain into 3 tiers. The first tier includes the type of pain: nociceptive, neuropathic, other, and unknown pain (see Table 1). ${ }^{9}$ The second tier divides the tier 1 pain into various pain subtypes, and the third tier is used to specify the source of the pain at the organ or pathological level. Note, for the "other" pain type, tier 3 is used to specify any pain entity or syndrome that does not fulfill any of the other categories. In this article we discuss only the classification of nociceptive and neuropathic pain types. Nociceptive pain is defined as pain generated from the activation of nociceptors located in peripheral tissues. A nociceptor is a peripheral nerve ending or a sensory receptor that is capable of transducing and encoding noxious stimuli. ${ }^{10}$ As noted in the ISCIP classification system, nociceptive pain can be divided in to musculoskeletal pain, visceral pain, and other nociceptive pain. Musculoskeletal (nociceptive) pain refers to the pain that arises from nociceptors within musculoskeletal structures such as muscle, tendons, ligaments, joints. or bones. To diagnose this class of pain, a patient must have at least some preserved sensation where the pain is located and be able to localize the pain. Also, the evidence of physical 
musculoskeletal pathology underlying the pain must exist. ${ }^{9}$ An unidentified underlying pathology or pain that does not respond to treatment for a presumed pathology may indicate the presence of at-level SCI neuropathic pain or below-level SCI neuropathic pain.

If pain is localized in the thorax, abdomen, or pelvis and a definitive pathology is identified, it is classified as visceral (nociceptive) pain. If there is no evidence of visceral pathology, atlevel or below-level (neuropathic) SCI pain should again be considered as a possible diagnosis. Examples of visceral (nociceptive) pain include pain from constipation, urinary tract infection, kidney stones, cholecystitis, and myocardial infarction. ${ }^{9}$ Pain that does not fall into the categories of musculoskeletal pain or visceral pain can be referred to as other (nociceptive) pain. Examples include pain from pressure sores or autonomic dysreflexia and headaches.

Neuropathic pain is divided into 3 subtiers including at-level SCI pain, below-level SCI pain, and other neuropathic pain and is defined as pain caused by a lesion or disease of the somatosensory system. ${ }^{11}$ The characteristics of neuropathic pain include sensory deficits within the pain distribution, allodynia or hyperalgesia within the pain distribution, and pain described as hot/burning, tingling, pricking, pins and needles, sharp, shooting, squeezing, painful cold, and electric shock-like. ${ }^{9,12,13}$

At-level SCI (neuropathic) pain is defined as neuropathic pain from a lesion or disease of a nerve root or the spinal cord that is experienced within the 3 dermatomes below the neurologic level of injury (NLI), one dermatome above the NLI, or both. ${ }^{9}$ If pain is thought to be caused by a lesion to or disease in the cauda equina, at-level SCI (neuropathic) pain can be experienced up to 6 dermatomes below the NLI.

Below-level SCI (neuropathic) pain refers to neuropathic pain more than 3 dermatomes below the dermatome of the NLI, excluding pain involving injury to or disease in the cauda equina. Individuals with SCI with complete and incomplete injuries can have below-level SCI (neuropathic) pain. Neuropathic pain with a similar distribution without evidence of a lesion or disease of a nerve root or the spinal cord should be classified as other neuropathic pain, ${ }^{9}$ which refers the neuropathic pain at any level and the existence of pathology that is not related to SCI. Diabetic neuropathy, compressive mononeuropathy such as carpal tunnel syndrome, or pain from lumbar radiculopathy are examples of other neuropathic pain.

Central neuropathic pain is a subcategory of neuropathic pain and is common in SCI. It can be defined as pain arising as a direct consequence of a lesion or a disease affecting the somatosensory system, in particular in the spinal cord and affecting the spinothalamocortical pathways. ${ }^{9,14}$ This includes the above-mentioned at-level and below-level SCI (neuropathic) pain.

\section{Assessment Of Central Neuropathic Pain}

In general, pain assessment in individuals with SCI is complex and requires a combination of standard general pain assessments, as well as medically specific questions unique to the patient's pathophysiology. Before assessing pain, clinicians should first determine the NLI and receive from patients a verbal description of the location, quality, distribution, intensity, 
periodicity, and duration of the pain as well as aggravating or relieving factors. A comprehensive and detailed pain history should include onset of any pain, circumstances, any past treatments, and course of pain. ${ }^{15}$ After this detailed pain history is obtained, pain evaluation tools and assessments can be properly performed.

Clinicians currently have several pain evaluation tools to establish an objective assessment of central neuropathic pain. However, none of them are specific to SCI neuropathic pain. ${ }^{16}$ Common tools to measure pain quality include the visual analog scale, the numeric rating scale, or the visual rating scale. Specific central neuropathic pain assessment tools include the Neuropathic Pain Scale (NPS), the Neuropathic Pain Symptom Inventory, and the selfcompleted Leeds Assessment of Neuropathic Signs and Symptoms. ${ }^{17}$ The NPS is a selfadministered, multidimensional assessment tool using descriptive terms of pain, such as "sharp, hot, dull, cold, sensitive, itchy, surface and deep."18 The Neuropathic Pain Symptom Inventory is also a self-administered assessment questionnaire evaluating different aspects of clinical neuropathic pain (Fig. 1). ${ }^{19}$

The self-completed Leeds Assessment of Neuropathic Signs and Symptoms was the first questionnaire designed for neuropathic pain diagnosis and, so far, it has the most empirical data showing that it properly distinguishes between patients with and without neuropathic pain among those with mixed chronic pain. However, given the lack of overlap in measures designed for this purpose, it is likely that the validity of any one measure could be improved by incorporating items. The NPS has the most empirical support as a measure of treatment outcome, although a new measure that includes the NPS items (the Pain Quality Assessment Scale) will likely prove to be even more useful because it includes additional pain descriptors not included on the NPS. ${ }^{16}$

Future assessment tools and scales will need to be developed to accurately manage and treat a patient with central neuropathic pain complaints from SCI. Scales that include patient selfassessment and logarithm-based questions may help capture a patient's pain complaints more accurately than current models.

\section{Pathophysiology of Central Neuropathic Pain After Sci}

It has been reported that up to $80 \%$ of patients with SCI develop or experience clinically significant neuropathic pain. ${ }^{6,20}$ Therefore, understanding the pathophysiology of central neuropathic pain is important. Although animal models of central neuropathic pain were first described in 1911, the pathophysiology and mechanisms of central neuropathic pain after SCI have only recently been given attention because of the development of relevant neuropathic pain animal models. ${ }^{21}$ Before the establishment and understanding of neuropathic pain mechanisms, patients with SCI were sometimes misdiagnosed as having a psychiatric disorder instead of a neuropathic pain condition. ${ }^{22}$ This clearly emphasizes the importance of understanding the mechanisms of central neuropathic pain.

SCI is followed by a primary and secondary cascade of events that lead to anatomical, neurochemical and excitotoxic, and inflammatory changes that ultimately lead to damage within the central nervous system, including the gray matter, white matter, and the bloodbrain barrier. ${ }^{23}$ Neurochemical and excitotoxic changes can cause the release of excitatory 
amino acids such as glutamate, produce free radicals and reactive oxygen species, and cause an imbalance in ionic gradients. These events have an interdependent relationship and collectively create an environment responsible for changing the functional and physiological state of spinal sensory neurons that may lead to the expression of different clinical conditions such as allodynia, hyperalgesia, and spontaneous pain. ${ }^{24}$ Anatomical changes also occur from necrosis and apoptosis of cells, gliosis, demyelination, cytoskeletal damage, and/or sprouting of axons. All of these changes can contribute to the hyperexcitability of higher neurons as well as disinhibition and imbalance of the pathway. ${ }^{24}$ Indeed, previous studies have shown that deafferentation of peripheral nerves may cause denervation hyperexcitability of higher neurons, and partial lesions may cause disinhibition or an imbalance between pathways. ${ }^{25}$

\section{Treatment}

Central neuropathic pain can start as early as 1 month after SCI. This acute neuropathic pain often does not resolve on its own, ${ }^{20,26}$ and treatment during this stage can prevent windup or plasticity changes in the central nervous system (CNS) that often lead to chronic central neuropathic pain. However, before pharmacological agents are prescribed, it is important to confirm that proper etiological factors such as correct seating position, proper transferring techniques, and correct application and use of bracing or other assistive equipment are being used. If the pain still persists, a number of pharmacological agents can be prescribed (Table 2). In the past, pharmacological treatment for SCI chronic pain has been through antiinflammatory agents. The idea behind these agents was that by reducing inflammation, pain would also be reduced. However, evidence has shown that anti-inflammatory drugs are more effective in treating musculoskeletal pain rather than chronic central SCI pain. ${ }^{27}$ As such, a wide variety of pharmacological agents have emerged as potential treatments for central neuropathic pain in patients with SCI. Many of these are detailed below and, as we will see, some may be more efficacious than others.

\section{A. Opioids}

Opiates, such as morphine, are currently more commonplace for chronic SCI pain, yet their use is somewhat controversial. ${ }^{28,29}$ Opiates exert their therapeutic effects through modulation of both central and peripheral pain pathways. Opioids interact with specific $\mu-$, $\kappa-$, and $\sigma$-receptors that block the release of neurotransmitters such as substance P. It is the $\mu$, receptor that exerts most of the analgesic and respiratory depression effects. $\mu$-Receptors can be broken into $\mu-1$ and $\mu-2$ receptors, where $\mu-1$ is hypothesized to mediate analgesia and $\mu-2$ is thought to mediate respiratory effects, dependence, and cardiac side effects. While evidence has supported the efficacy of opioid use in the management of acute pain in general, they are not commonly recommended for the treatment of patients with SCI with central neuropathic pain. ${ }^{28,29} \mathrm{~A}$ recent study, however, shows some evidence to the contrary: in patients with chronic central neuropathic pain (where 9 of 15 patients had stroke or SCI), Attal et al. ${ }^{30}$ showed that the intravenous use of morphine significantly decreased pain from brush-induced allodynia. Conversely, a recent Cochrane review of 2 randomized controlled trials and one nonrandomized study determined that there has not been sufficient evidence to indicate a difference between the effectiveness of methadone (a synthetic 
opioid) and placebo. ${ }^{31}$ This study, however, assessed chronic noncancer pain and was not specific to central neuropathic pain.

\section{B. Antiepileptics}

Antiepileptic agents also have been commonly used for the management of central neuropathic pain. Antiepileptics operate through various mechanisms including decreasing neuronal excitability by blocking sodium or calcium channels, enhancing the inhibitory effects of gamma-aminobutyric acid, or inhibiting excitatory glutaminergic transmission. ${ }^{32}$ Older agents such as valproate, carbamazepine, and phenytoin have been used in the past; however, controlled trials of some of these have failed to demonstrate significant improvements in chronic central pain for patients with SCI. ${ }^{33}$ To this end, newer antiepileptics such as gabapentin and pregabalin have emerged as possible replacements. Gabapentin and pregabalin are hypothesized to exert their effects through selective binding to the calcium channel subunit $\alpha 2-\delta$ in muscle tissue and brain. Through this selective binding process, both gabapentin and pregabalin are able to decrease the number of calcium channels at the synaptic junction in the spinal cord and therefore decrease the release of neurotransmitters involved in pain transmission. ${ }^{34}$ It is important to note that large randomized, controlled trials on gabapentin and pregabalin have shown an improved safety profile over the older antiepileptic agents. Indeed, studies have shown gabapentin's superiority over placebo for chronic SCI pain, ${ }^{35}$ and other randomized controlled trial have verified the efficacy of oral pregabalin for patients with SCI with central neuropathic pain, at least for 3-month increments. ${ }^{36}$ A recent study by Martinez et al. ${ }^{37}$ also demonstrated the analgesic effects of intranasal and intrathecal pregabalin administration in rats in a hypersensitive state caused by spinal nerve ligation and diabetic peripheral neuropathy models, further showing the potential benefits that antiepileptics can have on chronic neuropathic pain.

\section{Antispastics}

In general, antispasticity medications have been used for SCI only to alleviate spasticityvelocity-dependent increases in tone in response to the body's aberrant tonic stretch reflex. However, antispasticity medications such as baclofen and tizanidine are currently being considered for the management of central neuropathic pain in patients with SCI, yet the data is still relatively young.

Baclofen acts via an agonist action on the gamma-aminobutyric acid-B receptor and is typically administered either orally or intrathecally. Intrathecal baclofen is often the preferred method of administration because it acts directly on the CNS and results in more than 4 times the concentration in cerebrospinal fluid with only a fraction of the dose when compared with oral baclofen. While baclofen administration has been extensively researched for the management of spasticity after SCI, the effectiveness of its oral or intrathecal use for the management of central neuropathic SCI pain has not been well established. In 2011, however, a study found that oral baclofen was effective in reducing pain in a functional rat dyspepsia model. ${ }^{38}$ In additional, in a study involving 24 patients with SCI, baclofen was effective in reducing pain symptoms in half of the patient population. ${ }^{39}$ Kumru et al. ${ }^{40}$ also 
found that intrathecal baclofen was effective in modulating the heat pain perception threshold and heat pain-related evoked potentials in patients with SCI and severe spasticity.

Tizanidine, another antispastic agent, acts by binding to the central a-2 adrenergic receptors and inhibiting presynaptic motor neurons. ${ }^{41}$ Its effectiveness in reducing hypertonia and spasticity is comparable to that of oral baclofen, yet tizanidine has a better tolerability profile and it exerts its effects without the muscle weakness that may be associated with baclofen. ${ }^{42}$ Studies have shown that tizanidine also possesses effects that relieve central pain. In a study involving 47 patients after stroke, treatment with tizanidine produced a significant improvement in the intensity of spasticity-related pain. ${ }^{43}$

\section{Tricyclics}

Tricyclics are hypothesized to exert their effects through the inhibition of the reuptake of sodium and serotonin at neuronal terminals and through their effects on histamine, muscarinic, and opioid receptors. ${ }^{44}$ Tricyclics have been proven in the past to be effective agents for the treatment of peripheral neuropathy. Song et al. ${ }^{44}$ illustrated that intrathecal administration of tricyclics in combination with spinal cord stimulation produced a significant effect in reducing mechanical hypersensitivity in a rat model of central neuropathy. Although beneficial for peripheral neuropathy, there has been a lack of evidence for the use of tricyclics for the treatment of SCI central pain. ${ }^{45}$ A 6-week randomized, controlled study of the effects of amitriptyline on chronic neuropathic pain in patients with SCI found that it did not significantly decrease pain. ${ }^{46}$

\section{E. Anesthetics}

Research has shown mixed results related to the effectiveness of certain intravenous anesthetics in relieving central neuropathic pain. ${ }^{47-49}$ The use of lidocaine has been shown to significantly reduce components of central neuropathic pain in some cases ${ }^{48,50}$; yet in a recent study involving patients with abnormal spinal cord imaging and failed back surgery, the pain relieving effects of intravenous lidocaine was found to be no different than that of placebo saline, leaving questions about its effectiveness. ${ }^{51}$ Ketamine, on the other hand, has been shown to have more conclusive central neuropathic pain-relieving effects compared to lidocaine, as shown in a randomized, double-blind study involving 10 patients with SCI. ${ }^{52}$ The use of low-dose ketamine infusion also has been shown as an effective adjuvant therapy to oral gabapentin in patients with SCI-induced chronic pain. ${ }^{53}$

Although there is not yet conclusive evidence on the effectiveness of many of the aforementioned pharmacological agents for the treatment of central neuropathic pain, patients with SCI have tried them for chronic pain in general with some benefit.

Outside of pharmacological interventions, patients with SCI with chronic pain commonly pursue complementary, nonpharmacological treatments such as exercise, acupuncture, interventional treatments, and psychological treatment. Exercise-related treatments such as physical therapy and cardiac therapy have not been extensively studied; however, small clinical trials have indicated some effectiveness of these methods in reducing SCI pain. $.50,54$ Acupuncture also has become an increasingly popular method of treatment for chronic pain, but research involving the use of acupuncture in patients with chronic SCI pain has been 
limited. A study comparing the pain-reducing effects of acupuncture with those of shamacupuncture procedures reported significant reductions in pain in both groups. ${ }^{49}$ These studies, however, were underpowered. Other nonpharmacological treatments include massage and psychological interventions. However, the lack of large, placebo-controlled clinical trials of these treatments limits our ability to properly assess the potential effects they may have.

\section{Discussion}

Central neuropathic pain in the SCI population is an understudied area in clinical, translational, and basic research. Traditionally, there has not been an emphasis in treating chronic pain-related complaints among the SCI population, even though the majority of patients suffer from some form of chronic pain. Much of this is a result of the limited knowledge about SCI pain. A multidisciplinary approach to patient care, in addition to a better understanding of the pathophysiology and diagnosis of SCI pain, will lead to improved diagnosis, management, and treatment of these patients. In addition, we believe that more research should focus on improving methods and tools to properly identify and treat central neuropathic pain. Because of the field's limited understanding and experience in dealing with this particular SCI patient population, we have included a short section of our clinical recommendations based on our experience in this difficult area.

On the basis of our knowledge and experience, we recommend that clinicians first determine the NLI and receive from the patient a verbal description of the location, quality, distribution, intensity, periodicity, and duration of the pain as well as aggravating or relieving factors. A complete and detailed pain history should also include onset of any pain, its circumstances, the course of pain, and any past treatments.

In the setting of acute pain, it is important to prevent windup or plasticity changes in the CNS that may lead to chronic central neuropathic pain. First, we recommend that etiologies such as inappropriate seating positions or equipment, improper transferring techniques, or painful joint positions caused by the application of bracing as well as other assistive devices be corrected. If the pain persists after these corrections, pharmacological agents may be introduced. In our practice we use newer antiepileptics, such as gabapentin and pregabalin, or low-dose tricyclics such as amitriptyline or nortriptyline as the first line of pharmacological agents. If the pain is not sufficiently controlled by one of these agents, we recommend switching to a medication within the same class of medications to see whether one type works better than the other. If this still does not relieve the pain, a combination of different classes of medications may be tried. For example, we typically start either gabapentin or one of the tricyclic acids (TCAs). If the patient experiences unsatisfying relief of pain with the initial treatment, we switch from gabapentin to pregabalin or from one TCA to another. If the patient is still not satisfied with the level of pain relief, we provide a combination of gabapentin or pregabalin and a TCA. We reserve opioids as last resort, used only after various classes of medications or combination therapy fail.

In conjunction with pharmacological treatment, we recommend a multidisciplinary approach to pain treatment that includes administration of cognitive behavioral therapy, psychological 
therapy, and physical or occupational therapy. Alternative therapies such as acupuncture, massage, and exercise can also be used for pain refractory to standard pharmacological and multidisciplinary approaches. If medications and alternative therapies do not adequately control the pain, or if side effects from the medications are intolerable, a discussion with the patient with regard to invasive interventions such as an intrathecal pump (for pain or spasticity, depending on the pain generator) or a spinal cord stimulator is warranted.

By furthering the understanding of pathophysiology through animal models, correctly identifying certain pain subtypes, and using a multimodal, multidisciplinary team approach, we hope to improve the overall management and treatment of patients with SCI induced central neuropathic pain.

\section{References}

1. Spinal cord injury facts and figures at a glance. Birmingham (AL): The National SCI Statistical Center; [February 2012; cited 22 Nov 2013]. Available at: https://www.nscisc.uab.edu/ PublicDocuments/fact_figures_docs/Facts\%202012\%20Feb\%20Final.pdf

2. De Vivo MJ. Discharge disposition from model spinal cord injury care system rehabilitation programs. Arch Phys Med Rehabil. 1999; 80(7):785-90. [PubMed: 10414763]

3. McColl MA, Aiken A, McColl A, Sakakibara B, Smith K. Primary care of people with spinal cord injury: scoping review. Can Fam Physician. 2012; 58(11):1207-16. [PubMed: 23152456]

4. Widerstrom-Noga EG, Felipe-Cuervo E, Broton JG, Duncan RC, Yezierski RP. Perceived difficulty in dealing with consequences of spinal cord injury. Arch Phys Med Rehabil. 1999; 80(5):580-6. [PubMed: 10326925]

5. Yezierski RP. Pain following spinal cord injury: the clinical problem and experimental studies. Pain. 1996; 68(2-3):185-94. [PubMed: 9121805]

6. Finnerup NB, Johannesen IL, Sindrup SH, Bach FW, Jensen TS. Pain and dysesthesia in patients with spinal cord injury: a postal survey. Spinal Cord. 2001; 39(5):256-62. [PubMed: 11438841]

7. Murray RF, Asghari A, Egorov DD, Rutkowski SB, Siddall PJ, Soden RJ, Ruff R. Impact of spinal cord injury on self-perceived pre- and postmorbid cognitive, emotional and physical functioning. Spinal Cord. 2007; 45(6):429-36. [PubMed: 17228355]

8. Putzke JD, Richards JS, Hicken BL, Ness TJ, Kezar L, DeVivo M. Pain classification following spinal cord injury: the utility of verbal descriptors. Spinal Cord. 2002; 40(3):118-27. [PubMed: 11859438]

9. Bryce TN, Biering-Sorensen F, Finnerup NB, Cardenas DD, Defrin R, Lundeberg T, Norrbrink C, Richards JS, Siddall P, Stripling T, Treede RD, Waxman SG, Widerström-Noga E, Yezierski RP, Dijkers M. International spinal cord injury pain classification: part I. Background and description. March 6-7, 2009. Spinal Cord. 2012; 50(6):413-7. [PubMed: 22182852]

10. Loeser JD, Treede RD. The Kyoto protocol of IASP basic pain terminology. Pain. 2008; 137(3): 473-7. [PubMed: 18583048]

11. Jensen TS, Baron R, Haanpaa M, Kalso E, Loeser JD, Rice AS, Treede RD. A new definition of neuropathic pain. Pain. 2011; 152(10):2204-5. [PubMed: 21764514]

12. Cardenas DD, Turner JA, Warms CA, Marshall HM. Classification of chronic pain associated with spinal cord injuries. Arch Phys Med Rehabil. 2002; 83(12):1708-14. [PubMed: 12474174]

13. Defrin R, Ohry A, Blumen N, Urea G. Characterization of chronic pain and somatosensory function in spinal cord injury subjects. Pain. 2001; 89(2-3):253-63. [PubMed: 11166482]

14. Maija, Haanpää.; Hietaharju, AAH. Chapter 25. Central neuropathic pain. In: Kopf, A.; Patel, NB., editors. Guide to pain management in low-resource settings. Washington, DC: International Association for the Society of Pain; 2010. p. 189-94.Available at: http://www.iasp-pain.org/AM/ Template.cfm?

Section=Guide_to_Pain_Management_in_Low_Resource_Settings\&Template=/CM/ ContentDisplay.cfm\&ContentID $=12188$ 
15. Ullrich PM. Pain following spinal cord injury. Phys Med Rehabil Clin N Am. 2007; 18(2):217-33. vi. [PubMed: 17543770]

16. Calmels P, Mick G, Perrouin-Verbe B, Ventura M. Neuropathic pain in spinal cord injury: identification, classification, evaluation. Ann Phys Rehabil Med. 2009; 52(2):83-102. [PubMed: 19909700]

17. Jensen MP. Review of measures of neuropathic pain. Curr Pain Headache Rep. 2006; 10(3):15966. [PubMed: 18778569]

18. Appendix. Neuropathic pain scale. Neuropathic pain: a treatment challenge for practitioners. [cited 22 Nov 2013]. Available at: http://practicingclinicians.com/cms/wb/PCEv3/site/hs09_pdfs/nps.pdf

19. Bouhassira D, Attal N, Fermanian J, Alchaar H, Gautron M, Masquelier E, Rostaing S, LanteriMinet M, Collin E, Grisart J, Boureau F. Development and validation of the Neuropathic Pain Symptom Inventory. Pain. 2004; 108(3):248-57. [PubMed: 15030944]

20. Siddall PJ, McClelland JM, Rutkowski SB, Cousins MJ. A longitudinal study of the prevalence and characteristics of pain in the first 5 years following spinal cord injury. Pain. 2003; 103(3):24957. [PubMed: 12791431]

21. Jaggi AS, Jain V, Singh N. Animal models of neuropathic pain. Fundamen Clin Pharmacol. 2011; 25(1):1-28.

22. Hulsebosch CE. From discovery to clinical trials: treatment strategies for central neuropathic pain after spinal cord injury. Curr Pharm Des. 2005; 11(11):1411-20. [PubMed: 15853671]

23. Finnerup NB, Jensen TS. Spinal cord injury pain-mechanisms and treatment. Eur J Neurol. 2004; 11(2):73-82. [PubMed: 14748766]

24. Yezierski RP. Spinal cord injury pain: spinal and supraspinal mechanisms. J Rehabil Res Dev. 2009; 46(1):95-107. [PubMed: 19533523]

25. Wiesenfeld-Hallin Z, Aldskogius H, Grant G, Hao JX, Hokfelt T, Xu XJ. Central inhibitory dysfunctions: mechanisms and clinical implications. Behav Brain Sci. 1997; 20(3):420-5. discussion 435-513. [PubMed: 10097004]

26. Siddall PJ, Taylor DA, McClelland JM, Rutkowski SB, Cousins MJ. Pain report and the relationship of pain to physical factors in the first 6 months following spinal cord injury. Pain. 1999; 81(1-2):187-97. [PubMed: 10353507]

27. Arner S, Meyerson BA. Lack of analgesic effect of opioids on neuropathic and idiopathic forms of pain. Pain. 1988; 33(1):11-23. [PubMed: 2454440]

28. Kalso EAL, Dellemijn PL, Moore RA, McQuay HJ. Recommendations for using opioids in chronic non-cancer pain. Eur J Pain. 2003; 7(5):381-6. [PubMed: 12935789]

29. Wrigley PJ. Pharmacological interventions for neuropathic pain following spinal cord injury: an update. Top Spinal Cord Inj Rehabil. 2007; 13:58-71.

30. Attal N, Guirimand F, Brasseur L, Gaude V, Chauvin M, Bouhassira D. Effects of IV morphine in central pain: a randomized placebo-controlled study. Neurology. 2002; 58(4):554-63. [PubMed: 11865132]

31. Haroutiunian S, McNicol ED, Lipman AG. Methadone for chronic non-cancer pain in adults. Cochrane Database Syst Rev. 2012; (11):CD008025. [PubMed: 23152251]

32. Bialer M. Why are antiepileptic drugs used for nonepileptic conditions? Epilepsia. 2012; 53(Suppl 7):26-33. [PubMed: 23153207]

33. Drewes AM, Andreasen A, Poulsen LH. Valproate for treatment of chronic central pain after spinal cord injury. A double-blind cross-over study. Paraplegia. 1994; 32(8):565-9. [PubMed: 7970862]

34. Devor M. How does gabapentin relieve neuropathic pain? Pain. 2009; 145(1-2):259. author reply 259-61. [PubMed: 19539428]

35. Tai Q, Kirshblum S, Chen B, Millis S, Johnston M, DeLisa JA. Gabapentin in the treatment of neuropathic pain after spinal cord injury: a prospective, randomized, double-blind, crossover trial. J Spinal Cord Med. 2002; 25(2):100-5. [PubMed: 12137213]

36. Siddall PJ, Cousins MJ, Otte A, Griesing T, Chambers R, Murphy TK. Pregabalin in central neuropathic pain associated with spinal cord injury: a placebo-controlled trial. Neurology. 2006; 67(10):1792-800. [PubMed: 17130411] 
37. Martinez JA, Kasamatsu M, Rosales-Hernandez A, Hanson LR, Frey WH, Toth CC. Comparison of central versus peripheral delivery of pregabalin in neuropathic pain states. Mol Pain. 2012; 8:3. [PubMed: 22236461]

38. Liu LS, Shenoy M, Pasricha PJ. The analgesic effects of the GABAB receptor agonist, baclofen, in a rodent model of functional dyspepsia. Neurogastroenterol Motil. 2011; 23(4):356-61. e160-351. [PubMed: 21199535]

39. Jagatsinh Y. Intrathecal baclofen: its effect on symptoms and activities of daily living in severe spasticity due to spinal cord injuries: a pilot study. Indian J Orthop. 2009; 43(1):46-9. [PubMed: 19753179]

40. Kumru H, Kofler M, Flores MC, Portell E, Robles V, Leon N, Vidal J. Effect of intrathecal baclofen on evoked pain perception: An evoked potentials and quantitative thermal testing study. Eur J Pain. 2012; 17(7):1039-7. [PubMed: 23239275]

41. Mathias CJ, Luckitt J, Desai P, Baker H, el Masri W, Frankel HL. Pharmacodynamics and pharmacokinetics of the oral antispastic agent tizanidine in patients with spinal cord injury. $\mathbf{J}$ Rehabil Res Dev. 1989; 26(4):9-16. [PubMed: 2600869]

42. Wallace JD. Summary of combined clinical analysis of controlled clinical trials with tizanidine. Neurology. 1994; 44(11 Suppl 9):S60-8. discussion S68-9. [PubMed: 7970013]

43. Gelber DA, Good DC, Dromerick A, Sergay S, Richardson M. Open-label dose-titration safety and efficacy study of tizanidine hydrochloride in the treatment of spasticity associated with chronic stroke. Stroke. 2001; 32(8):1841-6. [PubMed: 11486114]

44. Song Z, Meyerson BA, Linderoth B. The interaction between antidepressant drugs and the painrelieving effect of spinal cord stimulation in a rat model of neuropathy. Anesthes Analges. 2011; 113(5):1260-5.

45. Max MB, Lynch SA, Muir J, Shoaf SE, Smoller B, Dubner R. Effects of desipramine, amitriptyline, and fluoxetine on pain in diabetic neuropathy. New Engl J Med. 1992; 326(19): 1250-6. [PubMed: 1560801]

46. Cardenas DD, Warms CA, Turner JA, Marshall H, Brooke MM, Loeser JD. Efficacy of amitriptyline for relief of pain in spinal cord injury: results of a randomized controlled trial. Pain. 2002; 96(3):365-73. [PubMed: 11973011]

47. Finnerup NB, Biering-Sorensen F, Johannesen IL, Terkelsen AJ, Juhl GI, Kristensen AD, Sindrup $\mathrm{SH}$, Bach FW, Jensen TS. Intravenous lidocaine relieves spinal cord injury pain: a randomized controlled trial. Anesthesiology. 2005; 102(5):1023-30. [PubMed: 15851891]

48. Attal N, Gaude V, Brasseur L, Dupuy M, Guirimand F, Parker F, Bouhassira D. Intravenous lidocaine in central pain: a double-blind, placebo-controlled, psychophysical study. Neurology. 2000; 54(3):564-74. [PubMed: 10680784]

49. Dyson-Hudson TA, Kadar P, LaFountaine M, Emmons R, Kirshblum SC, Tulsky D, Komaroff E. Acupuncture for chronic shoulder pain in persons with spinal cord injury: a small-scale clinical trial. Arch Phys Med Rehabil. 2007; 88(10):1276-83. [PubMed: 17908569]

50. Hicks AL, Martin KA, Ditor DS, Latimer AE, Craven C, Bugaresti J, McCartney N. Long-term exercise training in persons with spinal cord injury: effects on strength, arm ergometry performance and psychological well-being. Spinal Cord. 2003; 41(1):34-43. [PubMed: 12494319]

51. Park CH, Jung SH, Han CG. Effect of intravenous lidocaine on the neuropathic pain of failed back surgery syndrome. Korean J Pain. 2012; 25(2):94-8. [PubMed: 22514776]

52. Kvarnström A, Karlsten R, Quiding H, Gordh T. The analgesic effect of intravenous ketamine and lidocaine on pain after spinal cord injury. Acta Anaesthesiol Scand. 2004; 48(4):498-506. [PubMed: 15025615]

53. Amr YM. Multi-day low dose ketamine infusion as adjuvant to oral gabapentin in spinal cord injury related chronic pain: a prospective, randomized, double blind trial. Pain Physician. 2010; 13(3):245-9. [PubMed: 20495588]

54. Nawoczenski DA, Ritter-Soronen JM, Wilson CM, Howe BA, Ludewig PM. Clinical trial of exercise for shoulder pain in chronic spinal injury. Physical therapy. 2006; 86(12):1604-18. [PubMed: 17138842] 


\section{Abbreviations}

CNS central nervous system

ISCIP International Spinal Cord Injury Pain

NLI neurologic level of injury

NPS Neuropathic Pain Scale

SCI spinal cord injury

TCA tricyclic acid 
Neuropathic Pain Symptom Inventory (NPSI).

Neuropathic Pain Symptom Inventory

Severity of the spontaneous pain

Q1. Does your pain feel like burning?

Q2.Does your pain feel like squeezing?

Q3.Does your pain feel like pressure?

Q4. During the past $24 \mathrm{~h}$, your spontaneous pain has been present:

permanently / 8 to $12 \mathrm{~h} / 4$ to $7 \mathrm{~h} / 1$ to $3 \mathrm{~h} /<1 \mathrm{~h}$

Severity of the painful attacks

Q5.Does your pain feel like electric shocks?

Q6. Does your pain feel like stabbing?

Q7. In the past 24 h how many of these pain attacks have you had? $>20 / 11$

to $20 / 6$ to $10 / 1$ to 5 none

Severity of your provoked pains

Q8. Is your pain provoked or increased by brushing on the painful area?

Q9. Is your pain provoked or increased by pressure on the painful area?

Q10. Is your pain provoked or increased by contact with something cold on the painful area?

Severity of abnormal sensations

Q11. Do you fee 1 pins and needles?

Q12. Do you feel tingling?

Fig 1.

Neuropathic Pain Symptom Inventory. ${ }^{19}$ Reproduced with permission from the International Association for the Study of Pain. 
Table 1

International Spinal Cord Injury Pain (ISCIP) Classification9

\begin{tabular}{|c|c|c|}
\hline Tier 1: Pain type & Tier 2: Pain subtype & Tier 3: Primary pain source and/or pathology (write or type in) \\
\hline \multirow[t]{3}{*}{$\square$ Nociceptive pain } & $\square$ Musculoskeletal pain & $\begin{array}{l}\square \\
\text { e.g., glenohumeral arthritis, lateral epicondylitis, comminuted femur fracture, quadratus } \\
\text { lumborum muscle spasm }\end{array}$ \\
\hline & $\square$ Visceral pain & $\square_{\text {e.g., myocardial infarction, abdominal pain due to bowel impaction cholecystitis }}$ \\
\hline & $\square$ Other nociceptive pain & $\square \longdiv { \text { e.g., autonomic dysreflexia headache, migraine headache, surgical skin incision } }$. \\
\hline \multirow[t]{3}{*}{$\square$ Neuropathic pain } & $\square$ At level SCI pain & $\begin{array}{l}\square \\
\text { e.g., spinal cord compression, nerve root compression, cauda equine compression }\end{array}$ \\
\hline & $\square$ Below Level SCI pain & e.g., spinal cord ischemia, spinal cord compression \\
\hline & $\square$ Other neuropathic pain & $\begin{array}{l}\square . \text { e.g., carpal tunnel syndrome, trigeminal neuralgia, diabetic polyneuropathy } \\
\text {. }\end{array}$ \\
\hline$\square$ Other pain & & $\begin{array}{l}\square \\
\text { e.g., fibromyalgia, complex regional pain syndrome type I, interstitial cystitis, irritable } \\
\text { bowel syndrome }\end{array}$ \\
\hline$\square$ Unknown pain & & $\square$ \\
\hline
\end{tabular}


Table 2

\section{Pharmacological Management of Central Pain Syndrome}

\begin{tabular}{llll}
\hline Drug & Class & Effect & Comments \\
\hline Amitriptyline & Tricyclic acids & Inhibits norepinephrine and serotonin reuptake & Sedating effects \\
Baclofen & Muscle relaxants & Activates GABAb receptor & - \\
Carbamazepine & Anticonvulsants & Stabilizes the inactivated state of voltage-gated sodium channels & - \\
Dantrolene & Muscle relaxants & $\begin{array}{l}\text { Depresses excitation of skeletal muscle by binding to the ryanodine } \\
\text { receptor }\end{array}$ & $\begin{array}{l}\text { Central nervous system side } \\
\text { effects }\end{array}$ \\
Diazepam & Benzodiazepines & Bind and activates GABAa receptor & Careful use in patients with \\
Gabapentin & Anticonvulsants & $\begin{array}{l}\text { Increases the synaptic concentration of GABA, enhances GABA } \\
\text { responses Decreases glutamate }\end{array}$ & renal impairment \\
Ketamine & Anesthetics & Noncompetitive NMDA receptor antagonist & - \\
Tizanidine & Antispasmodics & $\begin{array}{l}\text { Binds to central a-2 adrenergic receptors to increase presynaptic motor } \\
\text { neuron inhibition }\end{array}$ & - \\
Morphine & Opiates & $\mu$-Opioid receptor agonist & -
\end{tabular}

GABA, gamma-aminobutyric acid; NMDA, N-methyl-D-aspartate. 